\title{
Water Inrush Mechanism Caused by Fault Activation Based on Stress Evolution of Surrounding Rock of Key Aquifer
}

\author{
Xiaorong Zhai ${ }^{1,2, *}$, Jiwen $\mathrm{Wu}^{1}$, Zhongsi $\mathrm{Dou}^{3}$, Kai Huang ${ }^{1}$, Guangtao Wang ${ }^{1}$ and Yangzhou $\mathrm{Ma}^{4}$ \\ ${ }^{1}$ School of Earth and Environment, Anhui University of Science \& Technology, Huainan 232001, China \\ 2 The Key Laboratory of Mine Geological Disaster Prevention and Control of Anhui Province, Huainan 232001, China \\ ${ }^{3}$ Huainan Vocational Technical College, Huainan 232001, China \\ ${ }^{4}$ ICB UMR 6303 CNRS, Univ. Bourgogne Franche-Comté, UTNM, F-90010, Belfort, France
}

Received 9 February 2017; Accepted 25 November 2017

\begin{abstract}
Water inrush accidents in coal mines are becoming increasingly serious with the increase in mining depth. Among these accidents, water inrush caused by fault activation is the most common. The water inrush mechanism cannot be revealed by the traditional method in determining whether the fault is activated by the displacement difference between the two walls of the fault. The fault Sun of Longdong coal mine was considered a research target, and the research methods of similar simulation test and numerical simulation were used based on the mining stress characteristics of surrounding rock of the key aquifer to investigate the water inrush mechanism and main control factors due to fault activation in mining. The mining characteristics of fault zone rock mass were analyzed in the process of coal pillar reduction, and the change in water inrush risk in the process of coal pillar reduction was revealed from the surrounding rock stress state of the key aquifer. Results show that the stress transfer law is evidently different in hanging wall and footwall. The stress state of the hanging wall rock near the fault zone is dominated by the compressive stress, whereas the stress state of the footwall changes with buried depth. The stress state of the surrounding rock roof of the key aquifer and fault zone changed from compressive to tensile stress, when the width of the coal pillar was $30 \mathrm{~m}$. The degree of pressure relief increases with depth, and the results obtained by the two methods are consistent. Evident shear failure occurs in the fault zone, and such failure is unfavorable for water prevention. The conclusions in this study provide theoretical basis to retain the coal pillar.
\end{abstract}

Keywords: Fault activation, Water inrush, Mining stress evolution, Aquifer

\section{Introduction}

Coal mining in China has undergone a rapid development stage. The demand for safe and efficient exploitation of coal resources increases with the adjustment of energy structure and the implementation of the national capacity to carry out policies. However, with the increase in mining depth, the geological conditions increasingly become complex, especially the increase in confined water pressure of the coal seam floor, thereby resulting in frequent accidents of water bursting. Moreover, the consequences of water inrush become serious, thereby providing considerable challenges to the safe and efficient mining of deep coal resources [1]. Water inrush caused by fault activation is one of the common water inrush methods in coal mine [2-4]. According to statistics, more than $70 \%$ of mine water inrush accidents are related to fault activation [5-7]. At present, the precursors, process, and main controlling factors of fault activation remain unclear. Therefore, establishing the discriminant mark before fault activation is considerably significant for mine safety production and an urgent solution to prevent water inrush caused by fault activation.

However, the existing achievements are mainly focused on the analysis and simulation test of the activation instability process of fault. The fault activation criterion is

*E-mail address: zhaixiaorong@sina.com

ISSN: $1791-2377$ @ 2017 Eastern Macedonia and Thrace Institute of Technology. All rights reserved. doi:10.25103/jestr.106.23 mainly determined by the displacement difference between the two fault walls [8-10]. The displacement difference is only the image, and its origin lies in the evolution of the mining stress, especially the influence of the stress evolution of the surrounding rock of the key aquifer.

Similar material simulation test and numerical simulation were adopted to analyze the evolution law of mining stress of two fault walls rock mass based on the preceding problems mentioned. The water inrush mechanism caused by fault activation induced by stress evolution of key aquifer surrounding rock is revealed to establish the stress identification mark of fault activation and obtain its main controlling factors, thereby providing scientific basis for the prediction and prevention of fault activation.

\section{State of art}

Domestic and foreign scholars have conducted a considerable among of research work from different angles to identify the water inrush mechanism caused by fault activation. The activation water inrush mechanism of tensile fault and compressive shear fault was studied based on the cusp catastrophe model. The risk function of fault water inrush was established, and the index of water inrush was put forward. The risk function has been successfully applied to the Jiaozhou Bay Subsea Tunnel in Qingdao [11]. Jiang et al. analyzed the evolution of mining stress and the motion characteristics of coal roof during the reversed fault 
activation process using numerical simulation method under the condition of different mining directions. The results showed that mining in the footwall of the reversed fault can easily lead to fault activation [12]. Zhang et al. simulated the water inrush process caused by fault activation during coal seam mining by the physical simulation test. The results showed that the mining stress of the hanging wall considerably reduced, and the water inrush was due to the failure zone connection of coal floor and the fault [13]. Liang et al. used field test method to test the water pressure resistance of the normal fault and put forward the failure capacity index of unit seepage to reflect whether the fault activation occurred [14]. Based on the Mohr-Kulun failure criterion, Hoffman studied the variation law of the slip zone cohesive force when fault activation was unstable and concluded that the change of cohesion was the key to the activation of faults [15]. Zhang et al. investigated the process of water inrush from fault caused by coal seam mining above the confined aquifer by physical simulation test and found that mining causes fault permeability enhancement, fault zone seepage flow from small to large which could be divided into three distinct phases, and the final fault generated activation of water inrush [16]. Wu et al. analyzed water inrush from fault with the combination of in-situ measurement and laboratory test. They concluded that the existence and development of the vulnerable area of the fault can be attributed to the water inrush due to the excavation influence of the roadway and the working face [17].

The transition law of the mining stress significantly changed during coal mining toward the fault due to the fault zone influence [18-20]. The stress evolution law of the fault zone rock, especially the key aquifer surrounding rock, plays a key role in controlling the fault zone activation.

Domestic and foreign scholars have focused on the mechanism of water inrush due to fault activation. However, certain deficiencies still exist. First, most analytical expressions are obtained by theoretical analysis and numerical simulation rather than similar material simulation. Second, the law of rock mass migration in the analysis process is mainly analyzed, whereas the law of stress evolution in rock mass is not considered, and the fault activation mechanism cannot be revealed.

A similar simulation and a numerical simulation program are designed based on the field data to analyze the stress evolution law of the near-fault rock mass and the surrounding rock of the key aquifer in the condition of different coal pillar widths given the preceding situations. The mechanism of water inrush due to fault activation is then revealed from the stress state of the surrounding rock of the key aquifer.

The remainder of this study is organized as follows. Section 3 establishes a similar material model and a numerical simulation model, which has received efficient and reliable data based on field core uniaxial compression tests of Longdong Mine to allow the parameters and spatial relationships to comply with actual circumstances. Stress evolution data are monitored to analyze the stress evolution law of the near-fault rock mass and the surrounding rock of the key aquifer. Section 4 summarizes and concludes the study.

\section{Methodology}

3.1 Engineering technology background of the coal mine The No. 7 coal seam, which belongs to Shanxi group of the Permian system of the second mining area with an average thickness of $5.0 \mathrm{~m}$, was taken as the research target according to the exploration data of the Longdong Coal Mine. The mining level range of No. 7 coal seam floor is from $-250 \mathrm{~m}$ to $-600 \mathrm{~m}$, and the average level is $-425 \mathrm{~m}$. The direct roof of coal seam is mudstone, and the old top is interbedded between siltstone and middle sandstone. The direct coal floor is mudstone. The No. 7 coal seam mining is threatened by the limestone aquifer of the Taiyuan group of Carboniferous system, which contains 12 layers of limestone aquifers. Among these layers, the 10th and 12th limestone aquifers are watery, thereby becoming the main threat to the coal seam mining. Fault Sun, which, was explored by underground drilling in the track tunnel, is the internal fault of the mining area. The fault is a normal fault with a dip angle of $70^{\circ}$ and a drop of $130 \mathrm{~m}$. The rock mass structure of fault Sun is fragmentation, and the width is $8 \mathrm{~m}$. Figure 1 shows drill cores of fault Sun. The vertical distance between No. 7 coal seam located at the hanging wall and the 10th and 12th limestone aquifer located at the footwall of the Taiyuan group of Carboniferous system decreased due to the fault Sun. Figure 2 shows the sketch of the fault Sun. Thus, the distance reduction increased the risk of water inrush caused by fault activation during mining.

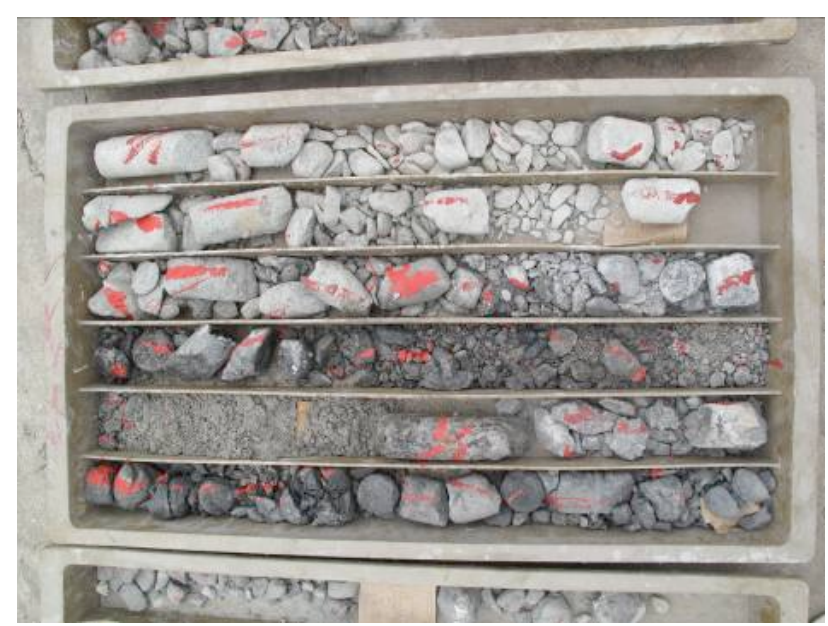

Fig. 1. Drill cores of the fault Sun

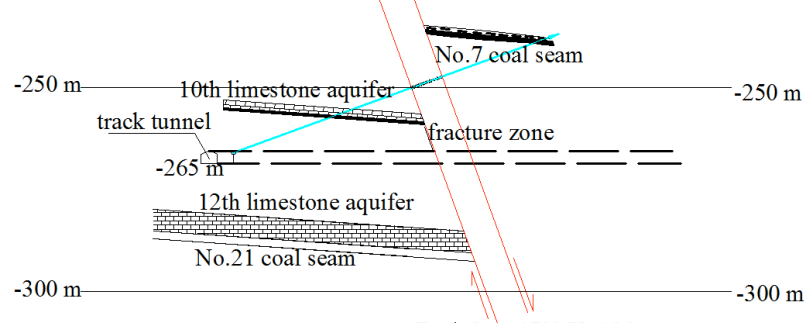

Fig. 2. Section sketch of the fault Sun

Fault Sun $\angle 70^{\circ} \mathrm{H}=130 \mathrm{~m}$

\subsection{Similar Physical Simulation}

\subsubsection{Model establishment and parameter selection}

A similar model was established based on similarity theorem [21]. The ratio of similitude in the simulation was determined as follows. Geometric similarity ratio is $\alpha_{l}=1 / 100$, and the volume weight similitude ratio is $\alpha_{\gamma}=0.6$. Finally, stress similitude ratio is $\alpha_{\sigma}=\alpha_{l} \times \alpha_{\gamma}=0.006$. Time similarity ratio is $\alpha_{t}=\sqrt{\alpha_{l}}=1 / 10$. River sand was used as aggregate, and lime powder and plaster were used as cement. The model was established based on the stratigraphic synthetic relation. Model geometry size was $300 \times 30 \times 150 \mathrm{~cm}$ (length $\times$ 
width $\times$ height). The similar model can simulate rock formations with actual thickness of $150 \mathrm{~m}$, thus containing $60 \mathrm{~m}$ rock formation below the No. 7 coal seam floor and 85 $\mathrm{m}$ rock formation above the No. 7 coal seam roof. The fault zone was relatively loose; thus, the fault Sun extended from the bottom of the model to the height of $120 \mathrm{~cm}$ to ensure the overall stability of the model after loading. The upper 30 $\mathrm{cm}$ was covered by horizontal rock formations. Figure 3 shows the similar material model. According to the strength similarity ratio, the rock strength at different sites was converted into parameters in the model. Table 1 shows the mechanical parameters of the analog simulation material.

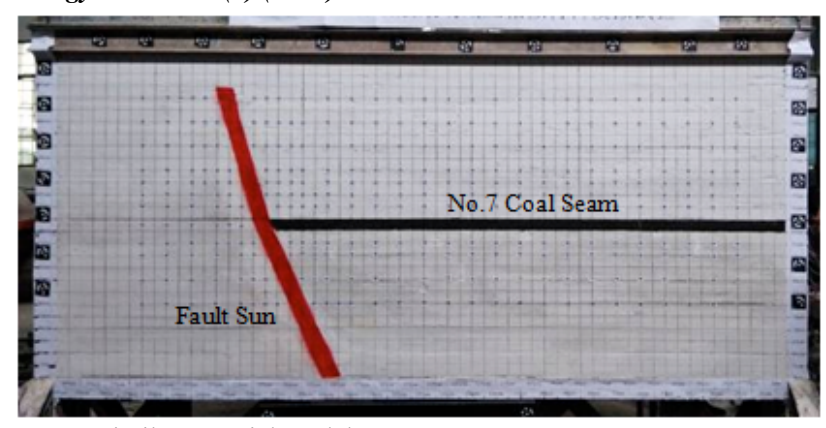

Fig. 3. Similar material model

Table 1. Mechanical parameters of similar material and prototype rocks

\begin{tabular}{|c|c|c|c|c|c|}
\hline $\begin{array}{l}\text { Serial } \\
\text { number }\end{array}$ & Rock stratum & $\begin{array}{c}\text { Uniaxial compressive } \\
\text { strength of rocks } \\
/ \mathrm{MPa}\end{array}$ & $\begin{array}{c}\text { Bulk density of } \\
\text { rocks } \\
1 \times 10^{3} \mathrm{Kg} / \mathrm{m}^{3}\end{array}$ & $\begin{array}{l}\text { Uniaxial compressive strength } \\
\text { of similar material / } \mathrm{MPa}\end{array}$ & $\begin{array}{c}\text { Bulk density of } \\
\text { similar material } \\
\quad / \times 10^{3} \mathrm{Kg} / \mathrm{m}^{3}\end{array}$ \\
\hline 1 & No. 7 coal seam & 8.20 & 1.40 & 0.09 & 0.85 \\
\hline 2 & Siltstone & 49.60 & 2.52 & 0.30 & 1.57 \\
\hline 3 & medium sand & 72.48 & 2.58 & 0.42 & 1.56 \\
\hline 4 & fine sandstone & 83.80 & 2.60 & 0.48 & 1.58 \\
\hline 5 & mudstone & 28.40 & 2.55 & 0.17 & 1.53 \\
\hline 6 & $\begin{array}{l}\text { 1st, } 2 \text { nd, and } 4 \text { th } \\
\text { limestone aquifer }\end{array}$ & 90.10 & 2.67 & 0.51 & 1.59 \\
\hline 7 & $\begin{array}{c}\text { 6th and 8th } \\
\text { limestone aquifer }\end{array}$ & 165.70 & 2.71 & 0.92 & 1.61 \\
\hline 8 & $\begin{array}{c}\text { 10th limestone } \\
\text { aquifer }\end{array}$ & 128.00 & 2.65 & 0.72 & 1.59 \\
\hline 9 & $\begin{array}{c}\text { 12th limestone } \\
\text { aquifer }\end{array}$ & 112.00 & 2.61 & 0.64 & 1.42 \\
\hline
\end{tabular}

\subsubsection{Monitoring point layout and mining process}

Resistance strain gauges were used to test the mining stress evolution law of both sides of the fault zone and the key aquifer in the footwall during the decrease in coal pillar width. The stress was calculated by the following formula:

$$
P=\mu \varepsilon \times k
$$

Where $P$ is the stress, $\mathrm{KPa} ; \mu \varepsilon$ is the strain; and $k$ is the constant coefficient determined by strain gauges.

The stress value is positive when the rock mass is under compression stress; conversely, the value is negative. Two vertical stress measuring lines were arranged in the hanging wall, when the coal pillar widths were $30 \mathrm{~cm}$ and $50 \mathrm{~cm}$. Seven monitoring points were available in each measured line at $5 \mathrm{~cm}$ and $15 \mathrm{~cm}$ from coal roof and 5, 10, 15, 30, and $45 \mathrm{~cm}$ from coal floor. Two stress measuring lines were placed in both sides of the fault zone to examine the evolution law of mining stress of the key aquifer surrounding rock and the effect of fault zone on the stress transfer in coal seam mining; each measuring line also had seven test points. Figure 4 shows the arrangement of measured points.

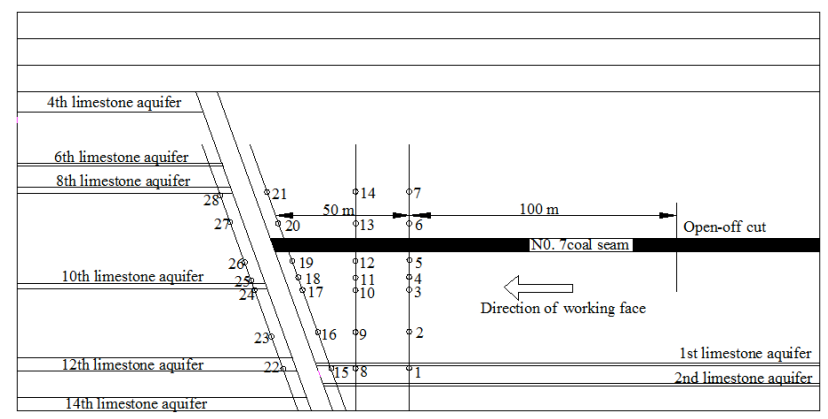

Fig. 4. Layout of monitoring points
Coal pillar reduction mining test was carried out, and the mining direction was from right to left toward the fault Sun. The width of the coal pillar was $50 \mathrm{~cm}$ on the right boundary of the No. 7 coal seam for restraining effect. The $10 \mathrm{~cm}$ width was mined for the first time. The $5 \mathrm{~cm}$ width was then mined every two hours, total mining $150 \mathrm{~cm}$. Finally, the data acquisition was stopped after stabilizing the stress transfer.

\subsubsection{Result analysis and discussion}

The mining stress evolution law of the No. 7 coal seam floor in different depths was analyzed during the reduction of coal pillar width. The results show that the horizontal stress transmission law was the same, thereby indicating that the stress peaks continue to move forward. The location of measuring points and mining distance indicated that the stress increase reached the maximum when the working face was pushed to $80-85 \mathrm{~cm}$. At this point, the distance from the working face to the stress measurement point was $20-35 \mathrm{~cm}$. The maximum stress concentration range ahead of the working face was $20-35 \mathrm{~m}$ according to the similitude ratio. The stress in the measuring line of the coal pillar width of 50 $\mathrm{cm}$ dropped to the minimum, when the working face mining is at $100 \mathrm{~cm}$. The stress in the measuring line of the coal pillar width of $30 \mathrm{~cm}$ dropped to the minimum, when the working face mining is at $120 \mathrm{~cm}$. The stress measurement points in the mined-out area were the result of the unloading of the mined-out area. The mining stress then increased again as the mined-out area was gradually compacted. Finally, the stress fluctuated and stabilized, as shown in Fig. 5.

The results from the stress measurement points near the fault zone show that the stress variation characteristics of different depths and positions were different. The stress variation law of $15 \#$ point, which was located at the depth of $45 \mathrm{~cm}$ under the coal floor, was consistent with the same 
depth of $13 \#$ and $8 \#$ measurement points. The value of $15 \#$ point reached the maximum, thereby indicating that the mining stress concentration in this position was the highest. By contrast, mining stress of $22 \#$ point, which is located at the same depth in footwall, was basically undulating and slightly changed and the stress was negative (Fig. 5a). The mining stress of $16 \#$ and $23 \#$ points, which were located at the same depth of $35 \mathrm{~cm}$ under the coal floor, was evidently different. In the early stage of working face mining, the variation law of the two points was basically the same. The increase range of mining stress reached the maximum when the working face mining is at $80 \mathrm{~cm}$; however, the value of $16 \#$ point was far larger than the stress of $23 \#$ point. When the mining distance was $90 \mathrm{~cm}$, the stress of $23 \#$ point suddenly decreased, thus changing from original integrity to negative. Therefore, the stress state of rock mass was changed from compression to tension, and the width of the coal pillar was $60 \mathrm{~cm}$. When the mining distance was 120 $\mathrm{cm}$, the stress of $23 \#$ point evidently decreased, and the tensile stress was further increased. The $23 \#$ measurement point was located at the upper part of the key aquifer of the 12 th limestone aquifer of the Taiyuan group. In practical engineering, tensile stress is not allowed in rock mass because the tensile strength of rock mass is less than that of the compressive strength. The tensile stress of the upper rock mass of the aquifer may lead to tensile destruction, which is a disadvantage that prevents water inrush from the fault zone (Fig. 5b). Simultaneously, the fault zone evidently demonstrated shear failure. Figure 6 shows the shear failure of the fault zone.

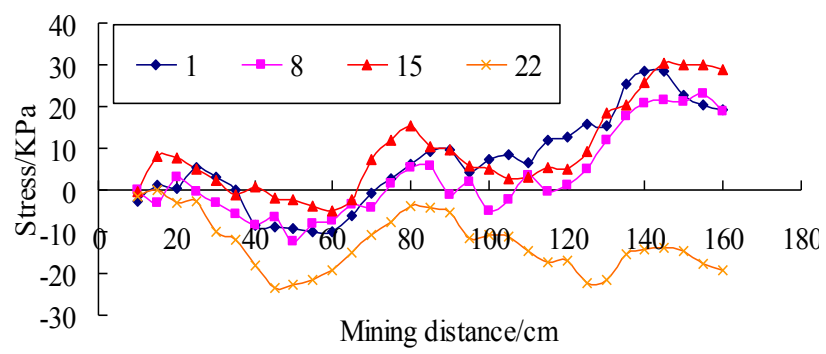

(a) $45 \mathrm{~cm}$ under the coal floor

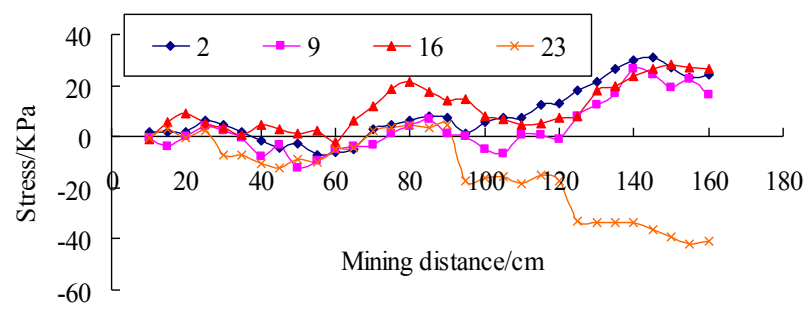

(b) $30 \mathrm{~cm}$ under the coal floor

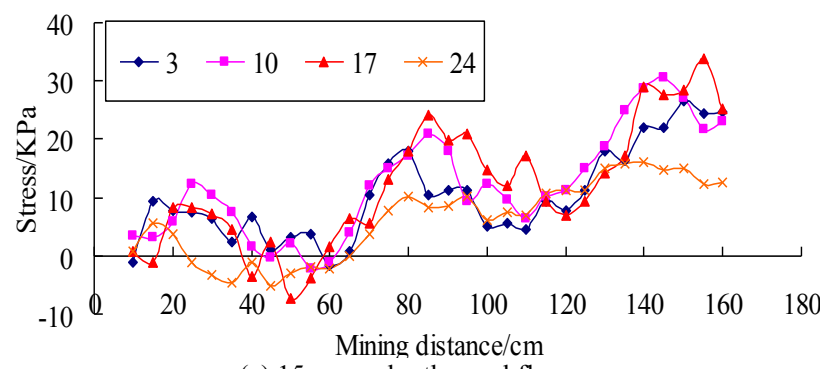

(c) $15 \mathrm{~cm}$ under the coal floor

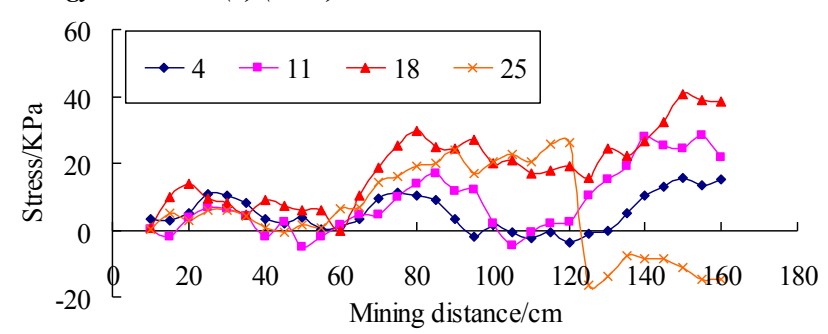

(d) $10 \mathrm{~cm}$ under the coal floor

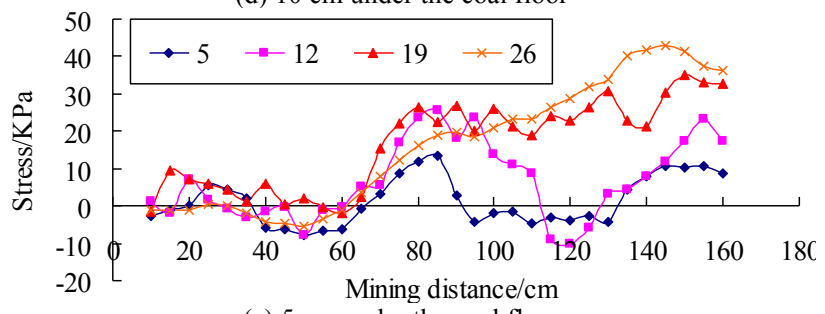

(e) $5 \mathrm{~cm}$ under the coal floor

Fig. 5. Monitoring results of different coal floor depths

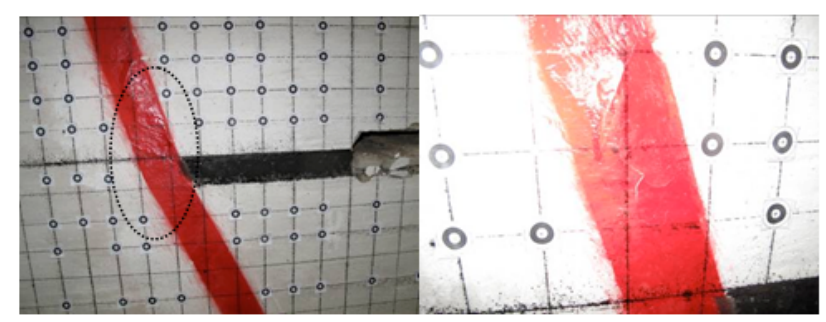

Fig. 6. Shear failure of fault zone

The stress state of the rock mass at the depth of $15 \mathrm{~cm}$ under coal floor was mainly compressive stress in both sides of the fault, and the value was nearly the same (Fig. 5c). The mining stress of $18 \#$ and $25 \#$ points, which were located at the same depth of $10 \mathrm{~cm}$ under the coal floor, was evidently different. In the early stage of the working face mining, the variation law of the two points was basically the same. When the mining distance was $130 \mathrm{~cm}$, the stress of $25 \#$ point suddenly decreased, thereby changing from original integrity to negative, and the width of the coal pillar was 20 $\mathrm{cm}$. The $25 \#$ measurement point was located at the upper portion of the key aquifer at the 10th limestone aquifer of the Taiyuan group. The prevention of water inrush is also disadvantageous. The stress values of $19 \#$ and $26 \#$ measurement points, which were located at a depth of $5 \mathrm{~cm}$ under the coal floor, were basically the same, thereby indicating that the mining stress was transmitted to the footwall through the fault zone (Fig. 5d).

The monitoring results of measuring lines above the No. 7 coal seam roof show that the variation law and increase range of mining stress of 20\#, 27\#, 21\#, and $28 \#$ were basically the same before the working face mining at $125 \mathrm{~cm}$. The increase range was evidently different after the mining distance exceeded $125 \mathrm{~cm}$. The stress increase range of $20 \#$ and $21 \#$ points located at the hanging wall of the fault expanded, whereas the increase range of $27 \#$ and $28 \#$ points located at the footwall did not change. Figure 7 shows the monitoring results of different coal roof heights. The results show that the mining stress of the hanging wall was not transmitted to the footwall through the fault zone, and this finding was different from the stress transfer law of coal floor rock mass. By contrast, the faults showed evident zonation in the vertical transfer direction of the mining stress. 


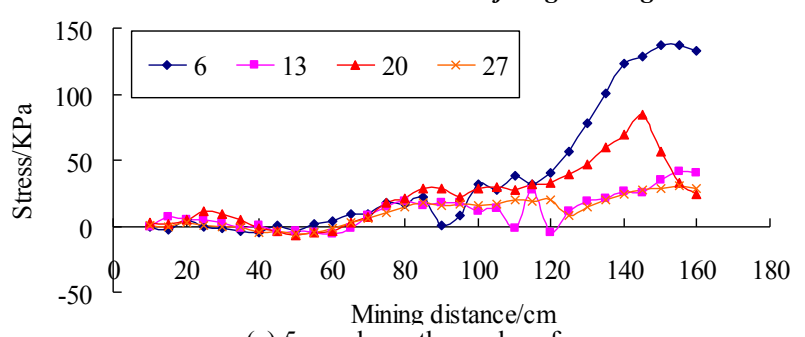

(a) $5 \mathrm{~cm}$ above the coal roof

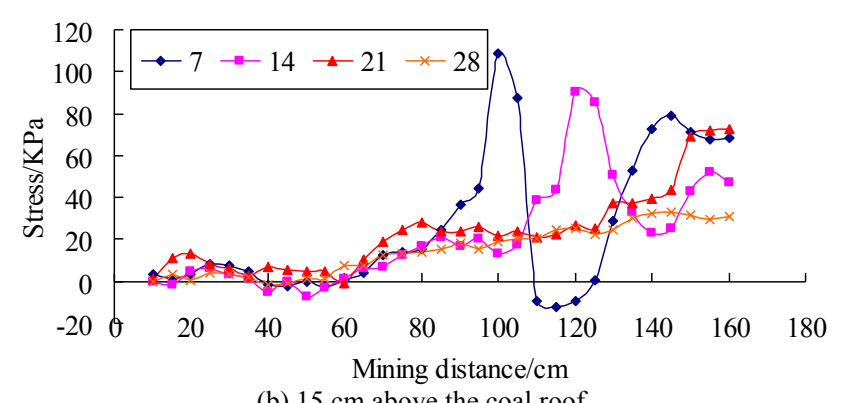

(b) $15 \mathrm{~cm}$ above the coal roof

Fig. 7. Monitoring results of different coal roof heights
The model was built by FLAC ${ }^{3 \mathrm{D}}$ software based on the geological conditions of the study area. The size of the model was $300 \times 250 \times 120 \mathrm{~cm}$ (length $\times$ width $\times$ height). Figure 8 shows the numerical model. The strength of the rock mass was calculated based on rock cores strength after reduction of the rock integrity coefficient. Table 2 shows the mechanical parameters of the numerical model.

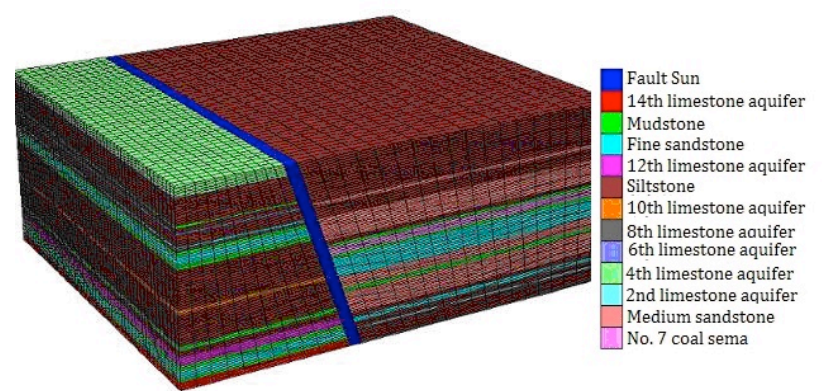

Fig. 8. Mesh diagram of the numerical model

\subsection{Numerical simulation}

3.3.1 Establishment of model and selection of parameters

Table 2. Mechanical parameters of the numerical model

\begin{tabular}{|c|c|c|c|c|c|c|}
\hline Lithology & $\begin{array}{c}\text { Bulk modulus } \\
/ \text { GPa }\end{array}$ & $\begin{array}{c}\text { Shear modulus } \\
\text { /GPa }\end{array}$ & Density $/ \mathrm{g} / \mathrm{cm}^{3}$ & $\begin{array}{l}\text { Cohesion } \\
\text { /MPa }\end{array}$ & $\begin{array}{c}\text { Internal friction } \\
\text { angle } /^{\circ}\end{array}$ & $\begin{array}{c}\text { Tensile strength } \\
\text { /MPa }\end{array}$ \\
\hline Medium sandstone & 11.46 & 10.80 & 2.64 & 4.00 & 35 & 2.80 \\
\hline Siltstone & 10.10 & 7.53 & 2.65 & 3.50 & 32 & 2.60 \\
\hline Fine sandstone & 8.40 & 6.68 & 2.65 & 2.40 & 30 & 2.40 \\
\hline mudstone & 1.19 & 1.26 & 2.38 & 2.00 & 28 & 1.50 \\
\hline No. 7 coal seam & 0.09 & 0.08 & 1.42 & 1.50 & 25 & 0.30 \\
\hline Fault zone & 0.10 & 0.06 & 1.80 & 0.60 & 22 & 0.05 \\
\hline $\begin{array}{l}\text { 2nd and 4th limestone } \\
\text { aquifer }\end{array}$ & 10.79 & 9.56 & 2.75 & 4.20 & 38 & 3.00 \\
\hline $\begin{array}{c}\text { 6th and 8th limestone } \\
\text { aquifer }\end{array}$ & 12.69 & 11.89 & 2.75 & 4.50 & 38 & 3.50 \\
\hline 10th limestone aquifer & 11.75 & 10.86 & 2.75 & 4.30 & 35 & 3.30 \\
\hline $\begin{array}{c}\text { 12th and 14th } \\
\text { limestone aquifer }\end{array}$ & 11.23 & 9.88 & 2.75 & 4.20 & 33 & 3.20 \\
\hline
\end{tabular}

\subsubsection{Excavation scheme and boundary conditions}

Long arm direction mining method was adopted, and the mining direction was along the fault trend. The width of the working face was $150 \mathrm{~cm}$, which adopted the mining height, and the roof was managed by free caving. The width of the coal pillar was calculated at $20,30,40,50,60$, and $70 \mathrm{~m}$ to investigate the evolution law of mining stress under the condition of different coal pillar widths.

The boundary conditions of the model were as follows: the bottom of the model was fixed, the horizontal direction was limited, the top was a free boundary, and the overburden load was applied. The calculation used the Mohr-Kulun criterion.

\subsubsection{Result analysis and discussion}

The stress state of the 10th and 12th limestone aquifer was examined in the condition of different coal pillar widths to investigate the stress state variation characteristics of the key aquifer in the footwall during working face mining. Figure 9 shows the stress variation of the surrounding rock of the key aquifer in the footwall.

Compared with the initial stress before mining, the stress relaxation zone was formed in the coal seam floor after coal mining. The stress relaxation zone of the hanging wall evidently influenced the stress state of the 10th and 12th limestone aquifer. Pressure relief appeared above the 10th limestone aquifer when the coal pillar width was less than 40 $\mathrm{m}$. The stress state of the rock mass above the 12th limestone aquifer changed from compression to tension when the width of the coal pillar was $30 \mathrm{~m}$. The stress curve began to appear upward, that is, the phenomenon of unloading occurred. Pressure relief occurred at the top of the aquifer, which was detrimental to its water resistance.

Compression stress state of the rock mass above the 10th and 12 th limestone aquifers was observed while the width of the coal pillar exceeded $30 \mathrm{~m}$; hence, the water inrush from coal floor and fault activation cannot be easily induced. The results of numerical simulation and similar material simulation were identical. 
Xiaorong Zhai, Jiwen Wu, Zhongsi Dou, Kai Huang, Guangtao Wang and Yangzhou Ma/

Journal of Engineering Science and Technology Review 10 (6) (2017) 179-185

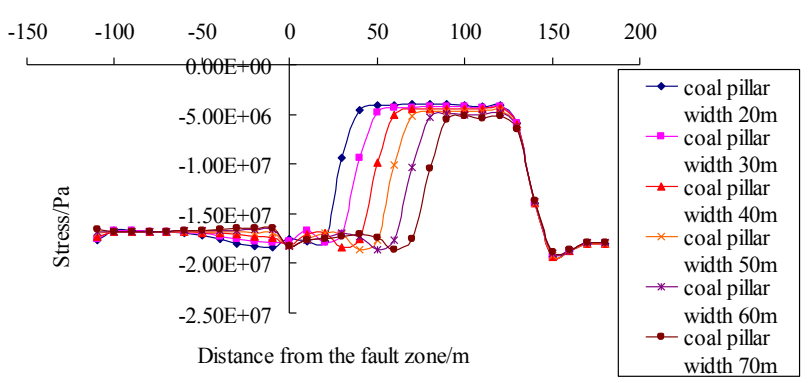

(a) Top of the 10th limestone aquifer

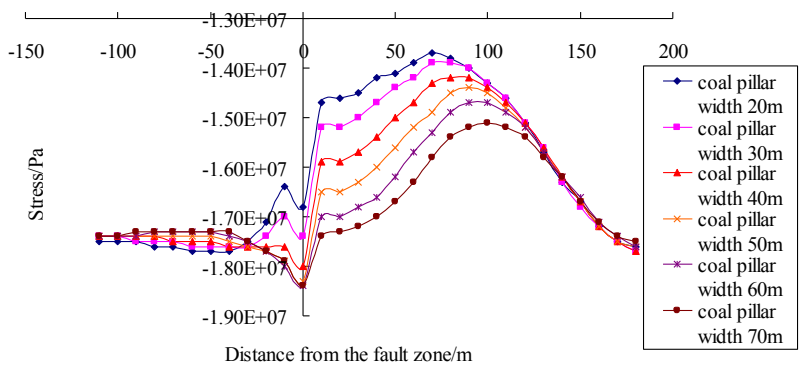

(b) Top of the 12th limestone aquifer

Fig. 9. Stress variation of the key aquifer surrounding rock in the footwall

\section{Conclusions}

A case study was conducted on the mining stress of nearfault zone rock and the surrounding rock of the key aquifer based on a similarity model test and a numerical model test to reveal the water inrush mechanism caused by fault activation during coal seam mining. Through the research on mining stress evolution law, the following conclusions are drawn:

1) The stress evolution law of the two walls of the fault is different, thereby showing vertical zonation. The stress evolution law and variation range of the two walls are similar under the coal seam floor. The stress evolution law is similar above the coal roof when the width of the coal pillar is more than $30 \mathrm{~m}$. The stress increase in the hanging wall is evidently larger than that at the same level of the footwall when the coal pillar width is less than $30 \mathrm{~m}$; that is, fault zone has a shielding effect on the mining stress.

2) The water inrush mechanism caused by fault activation is revealed from the surrounding rock stress evolution of the key aquifer. The stress state of the roof rock mass of the key aquifer changes from compression to tension when the coal pillar width is less than $30 \mathrm{~m}$, thereby leading to the rock crack. Moreover, shear failure appears in the fault zone, and the confined water may move into the working face along the fault zone.

3) Numerical simulation results agree with the results of similar material simulation. Pressure relief degree of the rock mass above the 12th limestone aquifer is larger than the 10th limestone aquifer. This result indicates that the degree of pressure relief increases with the increase in depth. The results can provide basis for the selection of coal pillar width.

4) The main control factor of water inrush caused by fault activation is the difference evolution of stress, and the stress mutation of the surrounding rock of the key aquifer is the key factor in fault activation.

A new understanding of fault activation caused by coal seam mining is proposed by combining the simulation test of similar materials with the numerical simulation analysis. The main control factor can be easily obtained because it is close to the actual situation. This factor provides a scientific basis for the prediction and prevention of water inrush caused by fault activation in deep coal resource mining. The fault activation rule can be accurately recognized by combining stress evolution monitoring data with experimental data in future studies due to the lack of actual data for monitoring the stress evolution of key aquifer surrounding rock.

\section{Acknowledgements}

The study was supported by the Key projects of Natural Science Foundation in Universities of Anhui (Grant No. KJ2017A073) and the research foundation for young teachers of Anhui University of Science \& Technology (Grant No. QN201612).

This is an Open Access article distributed under the terms of the Creative Commons Attribution Licence

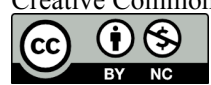

\section{References}

1. Xie, H. P., Zhou, H. W., Xue, D. J., Wang, H. W., Zhang, R., Gao, F., "Research and consideration of deep coal mining and extreme mining depth". Journal of China Coal Society, 37(4), 2012, pp. 536-542.

2. Zhang, P. S., Yan, W., Zhang, W. Q., Shen, B. T., Wang, H.,"Mechanism of water inrush due to damage of floor and fault activation induced by mining coal seam with fault defects under fluid-solid coupling mode". Chinese Journal of Geotechnical Engineering, 38(5), 2016, pp. 877-888.

3. Hua, X., Zhang, W. Q., and Jiao, D. Z, "Assessment method of water-inrush risk induced by fault activation and its application research". Procedia Engineering, 26, 2011, pp. 441-448

4. Petrie, E. S., Petrie, R. A., Evans, J. P., "Identification of reactivation and increased permeability associated with a fault damage zone using a multidisciplinary approach”. J Struct Geol, 59, 2014, pp. 37-49.

5. Hu, W. Y., Dong, S. N., Yan, L., "Water hazard control technology for safe extraction of coal resources influenced by fault zone". Procedia Earth and Planetary Science, 3, 2011, pp. 1-10.

6. Sui, W. H., Liu, J. Y., Yang, S. G., Chen, Z. S., Hu, Y. S., "Hydrogeological analysis and salvage of a deep coal mine after groundwater inrush". Environmental Earth Sciences, 62(4), 2011, pp. 735-749.

7. Li, Q. F., Wang W. J., Zhu, C. Q., Peng, W. Q., "Analysis of fault water-inrush mechanism based on the principle of water resistant key strata". Journal of Mining \& Safety Engineering, 26(1), 2009, pp. 87-90.

8. Zhu, G. A., Dou, L. M., Liu, Y., Su, Z.G., Li, H., Li, J., "Dynamic analysis and numerical simulation of fault slip instability induced by coal extraction". Journal of China University of Mining \& Technology, 45(1), 2016, pp. 28-33.

9. Zhang, W. Q., Sun, Q., Zhu, S. Y., Liu, D. Q., “Analysis of roof reverse fault instability- reactivation mechanism under mining". Coal Safety, 44(3), 2013, pp. 179-182.

10. Zhai, X. R., Wu, J. W., Shen, S. H., Han, Y., "Study on similar material simulation of rock mass mining stress at fault boundary". Journal of Safety Science \& Technology, 10(5), 2014, pp. 56-61.

11. Xue, Y. G, Wang, D., Li S.C., Qiu, D.H., Li, Z.Q., Zhu, J.Y. “A risk prediction method for water or mud inrush from water-bearing faults in Subsea tunnel based on cusp catastrophe model". KSCE J Civ Eng, 21, 2017, pp. 2607. 
Xiaorong Zhai, Jiwen Wu, Zhongsi Dou, Kai Huang, Guangtao Wang and Yangzhou Ma/

Journal of Engineering Science and Technology Review 10 (6) (2017) 179-185

12. Jiang, J. Q., Wu, Q. L., Qu. H., "Characteristic of mining stress evolution and activation of the hard-thick strata". Journal of China Coal Society, 40(2), 2015, pp. 267-277.

13. Zhang, S. C., Guo, W. J., Li, Y. Y., Sun, W. B., Yin, D. W., "Experimental simulation of fault water inrush channel evolution in a coal floor". Mine Water and the Environment, 36(3), 2017, pp. 443-451.

14. Liang, D. X., Jiang, Z. Q., Guan Y. Z., "Measuring water pressure resistance in a fault-induced fracture zone". Mine Water and The Environment, 34(3), 2015, pp. 320-328.

15. Hofmann G. F., Scheepers L. J., "Simulating fault slip areas of mining induced seismic tremors using static boundary element numerical modeling". Mining Technology, 120(1), 2011, pp. 53-64.

16. Zhang, R., Jiang, Z. Q., Zhou, H. Y., Yang, C. W., Xiao, S. J, "Groundwater outbursts from faults above a confined aquifer in the coal mining”. Natural Hazards, 71(3), 2014, pp. 1861-1872.

17. Wu Q., Wang M., Wu X., "Investigations of groundwater bursting into coal mine seam floors from fault zones". International Journal of Rock Mechanics \& Sciences, 41, 2004, pp. 557-571
18. Li, L. J., Yin, Y. Q., Qian, M. G., "Research on the tests of water inrush from floor simulated by similar materials". Coal Geology \& Exploration, 25(1), 1995, pp. 33-36.

19. Zhai, X. R., Wu, J.W., Han, D. Y., “Aquifer parameter calculation of pumping test of group holes with recharge boundary". Journal of China University of Mining \& Technology, 43(5), 2014, pp. 837840.

20. Dai, J., Jiang, J. Q., "Influence of mining sequence of hanging wall and foot wall on mining-induced stress of fault coal pillar". Journal of Mining \& Safety Engineering, 33(1), 2016, pp. 35-41.

21. Dou, Z. S., Wu, J. W., Wang, L., Zhai, X. R., Li, W. Q., Luo, L., Ma, Y. Z., "Similar physical simulation on the deformation of surrounding rocks of floor roadway caused by coal mining under tectonic stress". Journal of Engineering Science and Technology Review, 10(2), 2017,pp. 132-140. 